\title{
THE IDENTIFICATION OF ZACHERY-TREATED TURQUOISE
}

By Emmanuel Fritsch, Shane F. McClure, Mikhail Ostrooumov, Yves Andres, Thomas Moses, John I. Koivula, and Robert C. Kammerling

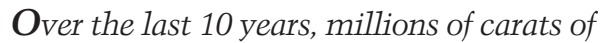
turquoise have been enhanced by a proprietary process called the Zachery treatment. Tests show that this process effectively improves a stone's ability to take a good polish and may or may not improve a stone's color. It also decreases the material's porosity, limiting its tendency to absorb discoloring agents such as skin oils. Examination of numerous samples known to be treated by this process revealed that Zachery-treated turquoise has gemological properties that are similar to those of untreated natural turquoise, and that the treatment does not involve impregnation with a polymer. Most Zachery-treated turquoise can be identified only through chemical analysis - most efficiently, by EDXRF spectroscopy—as it contains significantly more potassium than its untreated counterpart.

\section{ABOUT THE AUTHORS}

Dr. Fritsch (fritsch@cnrs-imn.fr) is professor of Physics at the University of Nantes, France. Mr. Moses is vice president for Research and Identification at the GIA Gem Trade Laboratory in New York. The late Mr. Kammerling was vicepresident for Research and Identification, Mr. McClure is manager of Identification Services, and Mr. Koivula is chief research gemologist at the GIA Gem Trade Laboratory in Carlsbad. Dr. Ostrooumov is professor at the St. Petersburg School of Mines, Russia, and currently professor at the Universidad de Michoacán de San Nicolás de Hidalgo, Michoacán, Mexico. Dr. Andres is assistant professor at the Nantes School of Mines, in Nantes.

Please see acknowledgments at end of article. Gems \& Gemology, Vol. 35, No. 1, pp. 4-16 (C) 1999 Gemological Institute of America

\begin{abstract}
urquoise is one of the oldest gem materials known. Its use in jewelry and for personal adornment can be traced back 70 centuries, to ancient Egypt (Branson, 1975). Today it is popular in fine jewelry worldwide (see cover and figure 1) as well as in various cultures, most notably among Native American groups of the southwestern United States (figure 2). However, because the supply of high-quality turquoise is limited, and because this material readily accepts many treatments, most turquoise is adulterated (Liddicoat, 1987). Cervelle (1985) even states that turquoise must be treated, to avoid the change in color caused by absorption of substances such as cosmetics, sweat, or grease into this typically porous material. The most common type of turquoise treatment is impregnation with an organic material. Such treatment can be readily detected by observation with a microscope, use of a hot point (Liddicoat, 1987), or infrared spectroscopy (Dontenville et al., 1986). However, there is a relatively new, proprietary turquoise treatment, commonly known in the trade as "enhanced turquoise" (again, see figures 1 and 2), which cannot be detected by any of these classical methods. The purpose of this article is to describe the properties of this treated turquoise, with the specific intent of offering a method for its identification.
\end{abstract}

\section{BACKGROUND}

At the 1988 Tucson show, one of the authors (RCK) was told that a new type of treated turquoise had been marketed for at least six months under the name "Zacharia-treated turquoise." This enhancement was reportedly done with chemicals such as copper sulfate (letter from Pat Troutman to RCK, February 24, 1988). Some of the material was being sold through R. H. \& Co. Inc. in Glendale, California. Inquiries to R. H. \& Co. were answered by Roben Hagobian. He stated that US\$1.5 million had been spent on developing this process, and that the treatment could not be detected. He also specified that it was not called "Zacharia treat- 
Figure 1. These pieces illustrate some of the fine turquoise jewelry and fashioned goods that are currently in the marketplace.

All of these pieces have been fashioned from

Zachery-treated turquoise from the Sleeping Beauty mine. The beads in the top necklace are $13 \mathrm{~mm}$ in diameter; the heart-shaped pendant is $35 \mathrm{~mm}$ wide; the cabochons in the earrings each measure $15 \times 20 \mathrm{~mm}$; and the larger stones in the rings are about $12 \mathrm{~mm}$ in largest dimension. Courtesy of Roben Hagobian; photo (C) Harold et Erica Van Pelt.

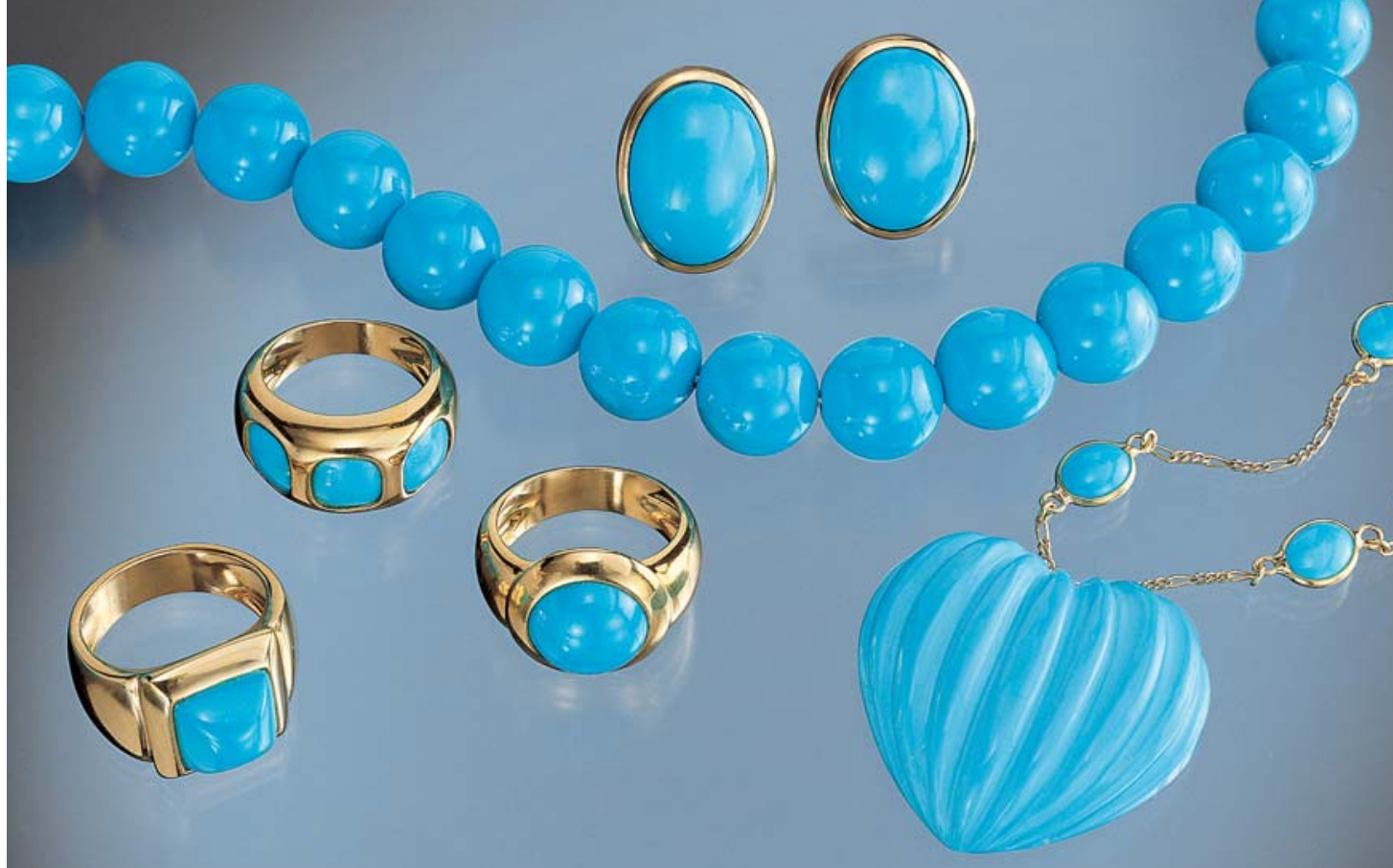

ment;" rather, that name probably referred to a scientist named Zachery who actually developed the procedure. Mr. Hagobian could not provide any details on the method himself, as he only provided the stones to be treated and got them back enhanced. At that time, we were also informed (through a letter dated June 23, 1989, from Pat Troutman to Loretta Bauchiero of GIA) that turquoise that was color-enhanced by this treatment might fade over time. No other information was made available to us, however, and our efforts to obtain additional samples and data were unsuccessful until recently.

At the end of 1996, we inadvertently encountered new information about the treatment in the course of another investigation. While researching polymer-impregnated turquoise, we were told of a company that was treating turquoise by a method that could not be detected. We subsequently learned that the material was being treated and marketed by Sterling Foutz of Sterling Products, Phoenix, Arizona. At the 1997 Tucson show, two of the authors (SFM and EF) met with Mr. Foutz, who agreed to supply a large number of treated samples from known turquoise mines around the world, as well as some untreated natural material from a number of these localities. Mr. Foutz told us that the process was invented by James E. Zachery, an entrepreneurial electrical engineer who "grew up" in the turquoise trade. It stemmed from a desire to improve the properties of turquoise without using artificial additives such as plastic. The key advantages of this treatment, according to Mr. Foutz, are that the treated stones take a better polish and are more resistant to "oxidation" or discoloration over time, apparently due to a significant decrease in the porosity of the turquoise. They can also apply the same process to produce a greater depth of color in the turquoise. More than 10 million carats of turquoise have been treated by this process since it was first invented in the late 1980s; Roben Hagobian (pers. comm., 1999) noted that in 1998 alone he had 1.2 million carats of turquoise enhanced by the Zachery process.

Mr. Foutz reported that the treatment process takes approximately three to six weeks, and that no organic or inorganic colorants or organic impregnations are used. Because the process is proprietary, Mr. Foutz did not provide specifics of the actual technique and asked us not to use the samples he supplied to research the precise technique. He did add, though, that the process only works on medi- 
TABLE 1. Turquoise samples studied by gemological testing and EDXRF analysis. ${ }^{a}$

\begin{tabular}{|c|c|c|c|c|c|c|c|c|}
\hline Description & $\begin{array}{l}\text { No. of } \\
\text { samples }\end{array}$ & $\begin{array}{l}\text { Sample } \\
\text { no. }\end{array}$ & $\begin{array}{c}\text { Year } \\
\text { acquired }\end{array}$ & Color & $\begin{array}{l}\text { Zachery } \\
\text { treated? }\end{array}$ & $\begin{array}{l}\text { FTIR } \\
\text { data? }\end{array}$ & $\begin{array}{c}\text { Size } \\
\text { (weight or } \\
\text { max. dim.) }\end{array}$ & Comments \\
\hline \multicolumn{9}{|l|}{ Sample Sets } \\
\hline \multirow[t]{3}{*}{ "Emerald Valley" b } & 2 & $220 a-b$ & 1998 & $\begin{array}{l}\text { Whitish } \\
\text { green; } \\
\text { green }\end{array}$ & $\begin{array}{l}\text { No }-1 \\
\text { Yes }-1\end{array}$ & No & $\begin{array}{l}21 \mathrm{~mm} \\
30 \mathrm{~mm}\end{array}$ & $\begin{array}{l}\text { Rough, sawn in half; } \\
\text { cabochons also made }\end{array}$ \\
\hline & 2 & $221 a-b$ & 1998 & Green & $\begin{array}{l}\text { No }-1 \\
\text { Yes }-1\end{array}$ & No & $\begin{array}{l}34 \mathrm{~mm} \\
20 \mathrm{~mm}\end{array}$ & $\begin{array}{l}\text { Rough, sawn in half; } \\
\text { cabochons also made }\end{array}$ \\
\hline & 2 & $222 a-b$ & 1998 & Green & $\begin{array}{l}\text { No }-1 \\
\text { Yes }-1\end{array}$ & No & $\begin{array}{l}40 \mathrm{~mm} \\
34 \mathrm{~mm}\end{array}$ & $\begin{array}{l}\text { Rough, sawn in half; } \\
\text { cabochons also made }\end{array}$ \\
\hline Sleeping Beauty, $A Z^{C}$ & 4 & $225 a-d$ & 1998 & Blue & Yes -4 & No & $11.22-18.28 \mathrm{ct}$ & $\begin{array}{l}\text { Cabochons, sawn in half: } \\
\text { surface treated only (a), } \\
\text { throughout }(b, c) \text {, } \\
\text { throughout } \\
+ \text { surface }(d)\end{array}$ \\
\hline Sleeping Beauty, $A Z^{d}$ & 4 & $231 a-d$ & 1998 & Blue & $\begin{array}{l}\text { No }-1 \\
\text { Yes - } 3\end{array}$ & No & $18-34 \mathrm{~mm}$ & $\begin{array}{l}\text { Rough, polished slabs: } \\
\text { untreated (a); treated } \\
\text { throughout (b), surface } \\
\text { treated (c), throughout } \\
\text { and surface (d) }\end{array}$ \\
\hline \multicolumn{9}{|l|}{ Other Samples } \\
\hline "Blue Bird"e & 3 & $164-166$ & 1997 & Med. blue & All samples & $\begin{array}{l}\text { All } \\
\text { samples }\end{array}$ & $18-24 \mathrm{~mm}$ & $\begin{array}{l}\text { Rough w/ matrix, polished; } \\
166 \text { had a partial blue rim }\end{array}$ \\
\hline China & 4 & $\begin{array}{l}362 \\
155-157\end{array}$ & $\begin{array}{l}\text { GIA } \\
1997\end{array}$ & Blue & $\begin{array}{l}\text { No }-1 \\
\text { Yes }-3\end{array}$ & $\begin{array}{l}\text { No }-1 \\
\text { Yes }-3\end{array}$ & $\begin{array}{l}13 \mathrm{~mm} \\
21-23 \mathrm{~mm}\end{array}$ & $\begin{array}{l}\text { Rough, sawn and polished } \\
\text { Rough w/ matrix, polished }\end{array}$ \\
\hline "Emerald Valley" & 4 & $\begin{array}{l}158-160 \\
170\end{array}$ & 1997 & Green & $\begin{array}{l}\text { All samples; } \\
2 \text { with } \\
\text { no evidence }\end{array}$ & All samples & $23-36 \mathrm{~mm}$ & $\begin{array}{l}\text { Rough w/ matrix, polished; } \\
\text { rough, sawn and polished }\end{array}$ \\
\hline Mexico & 3 & $152-154$ & 1997 & $\begin{array}{l}\text { Blue, } \\
\text { sl. gr. blue }\end{array}$ & All samples & All samples & $16-22$ mm & $\begin{array}{l}\text { Flat fragment w/ matrix, } \\
\text { polished; rough, polished }\end{array}$ \\
\hline Nevada (unspecified) & 1 & TQE4B & CRG & Greenish blue & No & Yes & $11 \mathrm{~mm}$ & Rough, polished \\
\hline Nevada Fox, NV & 3 & $161-163$ & 1997 & Green-blue & All samples & All samples & $17-21 \mathrm{~mm}$ & $\begin{array}{l}\text { Rough w/ matrix, polished; } \\
\text { rough, polished }\end{array}$ \\
\hline Nevada Smith, NV & 3 & $149-151$ & 1997 & Blue & All samples & All samples & $22-24 \mathrm{~mm}$ & $\begin{array}{l}\text { Rough w/ matrix, polished; } \\
\text { rough, polished }\end{array}$ \\
\hline Persia & 1 & 13925 & GIA & Blue & No & No & $28.78 \mathrm{ct}$ & Oval cabochon \\
\hline Sleeping Beauty, AZ & 5 & $141-145$ & 1997 & Blue & $\begin{array}{l}\text { No }-2 \\
\text { Yes }-3\end{array}$ & $\begin{array}{l}\text { All samples } \\
\text { All samples }\end{array}$ & $15-21 \mathrm{~mm}$ & $\begin{array}{l}\text { Rough, sawn and polished- } \\
\text { all with blue rim, less } \\
\text { pronounced on untreated }\end{array}$ \\
\hline Sleeping Beauty, AZ & 2 & $229-230$ & 1998 & Blue & No & No & $5.67,5.86 \mathrm{ct}$ & Beads \\
\hline "Thunder Blue" f (China) & 3 & $167-169$ & 1997 & Blue & All samples & All samples & $22-23$ mm & Rough w/ matrix, polished \\
\hline Turquoise Mtn., AZ & 3 & $146-148$ & 1997 & $\begin{array}{l}\text { Sl. gr. } \\
\text { blue }\end{array}$ & All samples & All samples & $21-27 \mathrm{~mm}$ & $\begin{array}{l}\text { Rough } \pm \text { matrix, broken; } \\
1 \text { polished, } 2 \text { unpolished }\end{array}$ \\
\hline U.S. (unspecified) & 1 & 172 & $\mathrm{EF}$ & Blue & No & Yes & $19 \mathrm{~mm}$ & Rough, sawn and polished \\
\hline Utah (unspecified) & 1 & 171 & $\mathrm{EF}$ & Blue & No & Yes & $22 \mathrm{~mm}$ & Rough w/ matrix, polished \\
\hline Uzbekistan & 1 & OST1 & $\mathrm{EF}$ & Blue & No & Yes & $20 \mathrm{~mm}$ & Flat slab w/ matrix, polished \\
\hline Unspecified locality & 6 & ZTT1-6 & 1988-89 & Blue & $\begin{array}{l}\text { All samples; } \\
1 \text { showed } \\
\text { no evidence }\end{array}$ & $\begin{array}{l}\text { Yes }-4 \\
\text { No }-2\end{array}$ & $0.49-4.39 \mathrm{ct}$ & $\begin{array}{l}\text { Cabochons - } 5 \text { (1 w/ matrix); } \\
\text { bead }-1\end{array}$ \\
\hline
\end{tabular}

a All samples were tested for refractive index (by the spot method), specific gravity (except Uzbekistan sample OST1, which had too much matrix), long- and short-wave UV radiation, visible spectrum (as seen with a hand-held spectroscope), and response to a thermal reaction tester. EDXRF chemical analysis also was performed on all samples. Abbreviations: max. dim. = maximum dimension, CRG = Centre de Recherches Gemmologiques Jean-Pierre Chenet (University of Nantes) collection, GIA = GIA collection, EF = Emmanuel Fritsch collection, gr. = greenish, sl. = slightly, med. = medium, $w /=$ with

${ }^{b}$ Refers to distinctly green turquoise from China, Mexico (Baja California), or the U.S. (New Mexico or Crescent Valley, Nevada).

c One surface-treated cabochon was analyzed by electron microprobe, before and after exposure to oxalic acid solution.

${ }^{d}$ All four slabs were analyzed by electron microprobe.

e Refers to medium blue turquoise from Mexico or the U.S. (Nevada or Arizona-Sleeping Beauty mine).

${ }^{f}$ The name given to turquoise from China by a particular supplier.

$g$ These samples were represented as treated, but they showed no $K$ peak with EDXRF. 
ed samples were from unspecified localities. The color varieties were designated as "Blue Bird" (three treated samples) and "Emerald Valley" (three untreated and seven treated samples). "Blue Bird" refers to medium blue turquoise; these samples could be from Mexico or the U.S. (Nevada or Arizona-Sleeping Beauty mine). "Emerald Valley" refers to turquoise with a distinctly green color; these samples could originate from China, Mexico (Baja California), or the U.S. (New Mexico or Crescent Valley, Nevada).

To test the durability and cutting performance of the treated material, we obtained from Mr. Foutz three rough samples that represented different qualities of "Emerald Valley" turquoise. Each sample was cut in half; one half was treated by the Zachery process (the precise treatment was not specified, but the same type was used on all), and the other was left untreated (figure 3). Subsequently, we had a cabochon fashioned from each half to compare both how well the treated and untreated materials responded to the cutting wheel and the relative quality of their polish. To test the effectiveness of the treatment in decreasing the porosity of the material, we cut fragments of the treated and untreated samples in half, and immersed one half of each in Johnson's ${ }^{\circledR}$ baby oil for a total of six days. The samples were removed from the oil and examined regularly during this period.

To characterize turquoise with different treatment types, we asked Mr. Foutz to treat a series of slabs from the same piece of rough. A nodule from the Sleeping Beauty mine was cut into four slabs (figure 4), and the following samples were prepared: (1) untreated, (2) surface treated only with the color enhanced,(3) treated throughout and left natural color, and (4) treated throughout and then surface treated to improve the color. This sample suite allowed us to make direct comparisons between the samples-before and after treatment, and between the different treatments - on a single piece of rough.

Also at our request, Mr. Foutz supplied four cabochons of treated Sleeping Beauty turquoise that we cut in half to observe changes in coloration. Two of these cabochons were treated throughout, one was surface treated only (with the color enhanced), and one was treated throughout and then surface treated to improve the color.

To investigate the color stability of the treated material, we took the three cabochons we had cut from the treated halves of the Emerald Valley treated-and-untreated specimens described above and sawed them in half. We placed one half of each sample in an Oriel 81150 solar simulator with a 300watt xenon light source. This instrument creates an output emission that approximates the daylight spectrum at two times its normal intensity. We left the cabochons in the solar simulator for 164 hours, checking them at approximately 24 hour intervals. This is equivalent to approximately 328 hours of noon sunlight exposure. The second half of each cabochon was kept in the dark as a control.

All of the samples were tested by the following methods, with the exception of the one untreated turquoise from Uzbekistan, for which specific-gravity testing would have been meaningless because it contained so much matrix material. Indices of refraction were measured by the spot method with a GIA Gem Instruments Duplex II refractometer. Specific gravity was determined by the hydrostatic

Figure 3. These samples (nos. 220-222a,b; 20-40 mm long) of rough "Emerald Valley" turquoise illustrate the results of treatment on different qualities of material. Half of each sample was treated by the Zachery process, and the other half was left untreated for comparison. Little change is visible in the treated half (top) of the high-quality (low-porosity) material in A. The medium-quality turquoise in $B$ shows distinctly higher color saturation in the treated half (right sample), as does the low-quality material in C (also right). Photos by Maha DeMaggio.
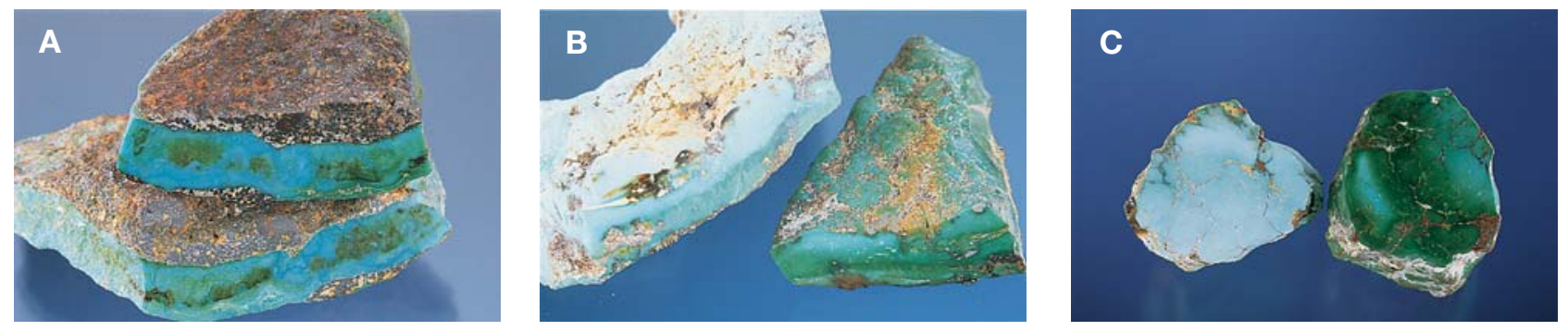
Figure 4. These four slabs (nos. 231a-d; 18-34 mm wide) were cut from the same piece of Sleeping Beauty mine rough. Three of the slabs were treated by the Zachery process to obtain different results.

From left to right: (1) untreated, (2) surface treated only to enhance color, (3) treated throughout and left natural color, and (4) treated through out and then surface treated to improve the color. Photo by Maha DeMaggio

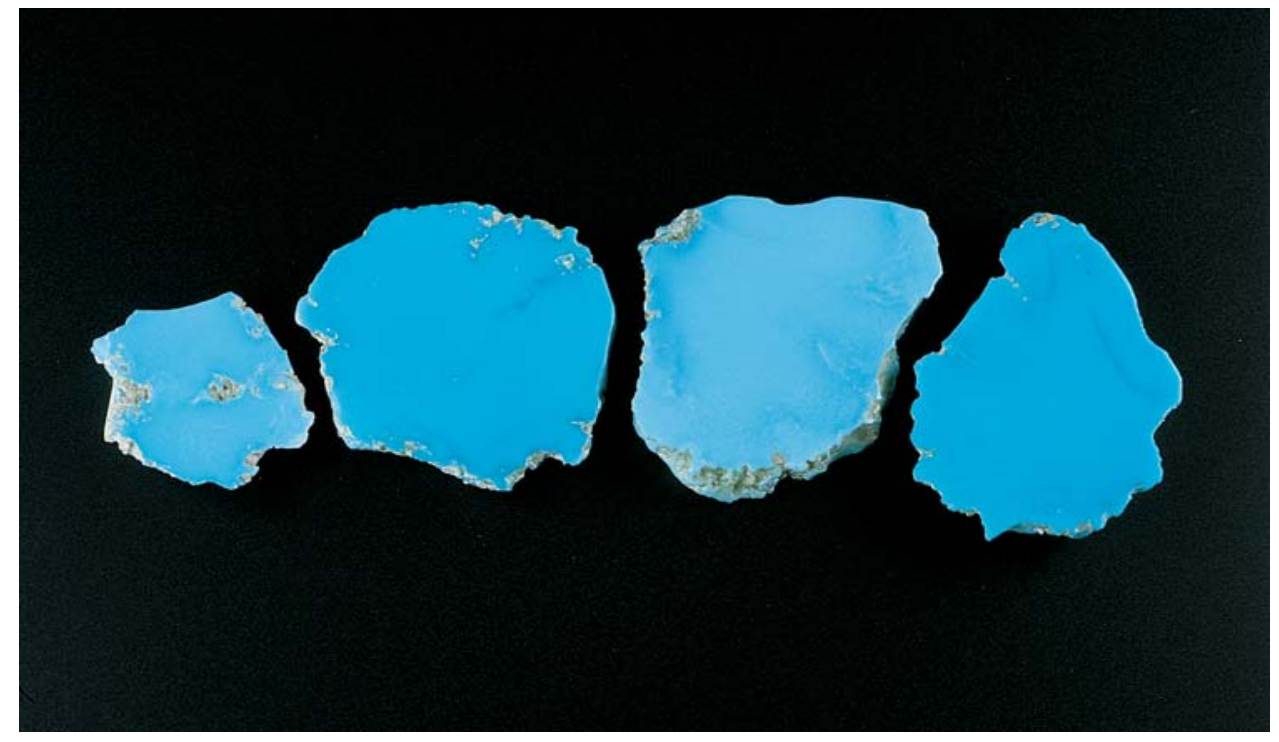

method. We also observed the samples with a Beck prism spectroscope, and a long-wave $(366 \mathrm{~nm})$ and short-wave $(254 \mathrm{~nm}$ ) ultraviolet lamp unit (in a darkened room). We applied a standard thermal reaction tester (TRT) to check for the presence of a polymer.

We performed Fourier-transform infrared spectroscopy (FTIR) on most of the samples (see table 1) using a Nicolet 20 SXC instrument in the specular reflectance mode, at a resolution of $4 \mathrm{~cm}^{-1}$, in the mid-infrared range 4000-400 $\mathrm{cm}^{-1}$. Semi-quantitative chemical analyses by energy-dispersive X-ray fluorescence (EDXRF) were obtained on all the study samples on either of two instruments: a Tracor Spectrace 5000 at GIA or an Oxford Instruments ED2000 at Nantes. The Spectrace 5000 had a rhodium anticathode, whereas the ED2000 had a silver anticathode. Instrumental artifacts caused by the machines, in particular the silver anticathode, were visible in the spectra collected; these could conceal the presence of small amounts of silicon or chlorine. The conditions were chosen to be appropriate for the simultaneous measurement of peaks for light elements (such as aluminum) through the end of the first series of transition elements (copper and zinc). For the Spectrace 5000 , the analyses were performed in a vacuum, with no filter, and with a tube voltage of $15 \mathrm{kV}$ and a livetime of 100 seconds. The same conditions were used for the ED2000, except for a tube voltage of $10 \mathrm{kV}$ and a livetime of 120 seconds.

Dr. F. C. Hawthorne at the University of Manitoba, Canada, performed electron microprobe analyses on (1) all four slabs from the Sleeping
Beauty mine and (2) one of the color-treated Sleeping Beauty cabochons that had been cut in half and one half immersed in oxalic acid. Cross-sections of the slabs were analyzed to provide quantitative chemical data near the surface and within the core of each sample. The analyses were performed using a Cameca SX-50 microprobe with an accelerating voltage of $15 \mathrm{kV}$, sample current of $20 \mathrm{nA}$, and a beam spot size of 20 microns. Dr. Hawthorne also performed X-ray diffraction analysis, using transmission geometry, on one untreated and two of the treated slabs.

\section{RESULTS}

Effectiveness of the Treatment. The three green "Emerald Valley" samples for which one half was treated and the other half was left in its original state illustrate the potential influence of the process on various aspects of appearance, cuttability, and durability. Two of the treated halves were much more saturated than their untreated counterparts, and some areas of matrix were a darker brown. The somewhat chalky appearance of these pieces before treatment disappeared after treatment. The color of the third sample was unaffected by treatment.

As noted above, one of the advantages claimed for Zachery-treated turquoise is that it is easier to cut and takes a better polish. According to the cutter of the six cabochons fashioned from these treated and untreated halves of "Emerald Valley" rough, all of the treated material was easier to work in that it gave a cleaner cut that did not crumble or splinter along the sawn edge. Indeed, the cutter had difficulty keeping the lowest-quality untreated material 

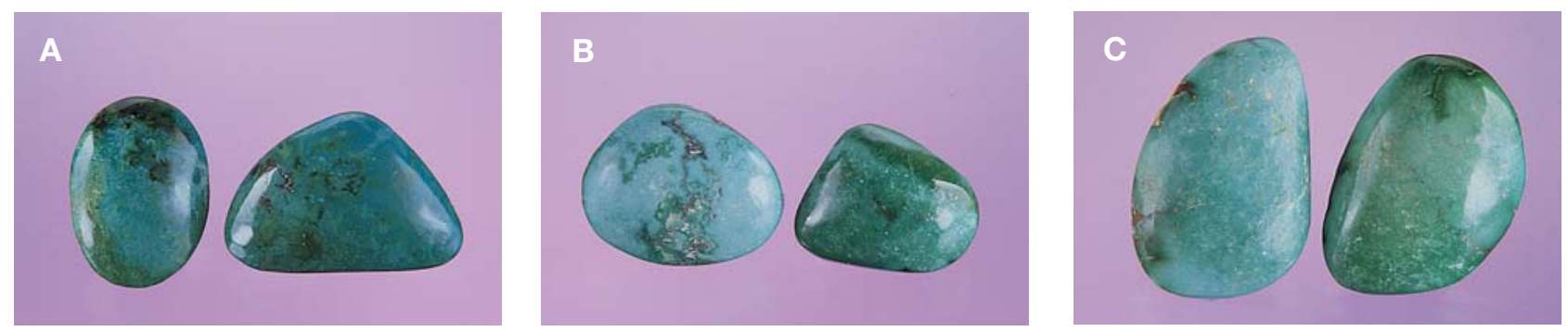

Figure 5. Cabochons were fashioned from the treated and untreated rough photographed in figure 3 so that we could compare the cuttability of the material. In each photo, the half fashioned from the treated piece of rough is shown on the right. Note especially the distinct improvement in luster in the treated stones, with the most pronounced difference seen in the lower-quality material (B and C). Photos by Maha DeMaggio.

from breaking up during sawing. The three Zacherytreated turquoise cabochons also took a better polish than the untreated material, with the lowestquality turquoise showing the most pronounced difference (figure 5). In fact, the unusually high luster was somewhat superior to what one would normally expect from high-quality untreated turquoise.

Another advantage claimed for Zachery treatment is that it reduces the tendency of turquoise to absorb oil and/or grease (by decreasing the porosity). We tested this claim by immersing fragments of these same samples in baby oil (while retaining portions of these fragments as controls). Within a few minutes, we observed that more air bubbles were escaping from the untreated fragments, which indicates that they were more porous than their treated counterparts. After six days of immersion, the three treated fragments did not show any change in appearance, but their untreated counterparts became noticeably to dramatically darker than the control samples. This illustrates that the treated turquoise has little or no tendency to absorb oil and grease, which would cause it to discolor over time, as does natural turquoise (Bariand and Poirot, 1985).

As noted earlier, some concern was expressed in the trade that Zachery-treated turquoise might fade over time. After exposure for 164 hours in a solar simulator, however, the three treated "Emerald Valley" cabochon halves did not show any fading or other change of appearance when compared to the control samples.

Gemological Properties. The samples ranged from blue through greenish blue to green (again, see table 1). The vast majority were the typical greenish blue color associated with turquoise. However, all of the samples labeled "Emerald Valley" were whitish green to green, as were two samples from Nevada Fox. Most of the rough samples showed various amounts of matrix admixture. On their natural, unpolished surfaces, the rough samples also revealed the botryoidal morphology typical of turquoise.

In general, the treated samples had darker, more saturated colors than their untreated counterparts. These colors are slightly unnatural in appearance and can be used as an indication of treatment, even though the difference is subtle and would require some experience to discern. Of the four Sleeping Beauty slabs cut from the same piece of rough, the one that was not color treated remained the same color as the untreated slab, whereas the surfaces of the two color-treated samples were darker and slightly more saturated than the underlying material.

To determine if there was a visible penetration of color in the treated material, we sawed in half (and polished the sawn edges) of the four Sleeping Beauty cabochons of known treatment type. The color-treated cabochons showed a layer of darker color that was subtle but clearly visible (figure 6). The penetration depth ranged from approximately 0.2 to $0.5 \mathrm{~mm}$ in these specimens.

For all samples-both untreated and treatedthe refractive index ranged from 1.60 to 1.62 (spot method). The specific gravity ranged from 2.61 to 2.74. These values are well within those reported for natural, untreated turquoise.

When examined with the hand spectroscope, all samples-again, both treated and untreatedshowed the band at about $430 \mathrm{~nm}$ that is characteristic of turquoise. In addition, all samples luminesced a weak to moderate whitish blue to longwave UV radiation and were inert to short-wave UV. None of the samples, whether natural or Zachery treated, showed any response to the thermal reaction tester.

When viewed with the gemological microscope, all samples revealed a typical turquoise structure with minor cavities and occasional pyrite and calcite inclusions. The treated samples did not reveal 
any of the characteristics that are common to turquoise treated by more traditional methods (such as evidence of filler materials in surface-reaching fractures and cavities). We did not observe fillers in any of the Zachery-treated samples we examined.

In fact, there was only one distinctive difference visible in any of the treated samples-concentrations of color along fractures-and it was only visible in some of them. This was best illustrated in the treated slabs from Sleeping Beauty that were cut from the same piece of rough and then processed differently. We did not see any color concentrations along fractures in the untreated slab or two of the treated slabs. However, the slab that was first treated all the way through and then surface treated to improve its color showed distinct concentrations of dark blue along fractures (figure 7). The color concentrations were not confined to the fracture itself, but rather they also penetrated the turquoise on either side of the break. This is an important observation, since low-quality turquoise that is impregnated and dyed will often show concentrations of color along fractures, but those concentrations consist of a colored filler material and are confined to the fracture itself (figure 8). Either type of color concentration is unnatural and, in our experience, does not occur in untreated turquoise.

Infrared Spectroscopy. Reflectance infrared spectroscopy of natural and treated samples in the midinfrared range produced similar spectra for both groups. Both showed major peaks at approximately 1125,1050 , and $1000 \mathrm{~cm}^{-1}$, which represent vibrations of the $\mathrm{PO}_{4}$ units; they did not show the peaks expected for polymer impregnation or organic compounds (for details, see Dontenville et al., 1986). These spectra also confirm that the samples tested were indeed natural, and not synthetic turquoise. The width of the peak, which was similar for both the untreated and Zachery-treated turquoise,

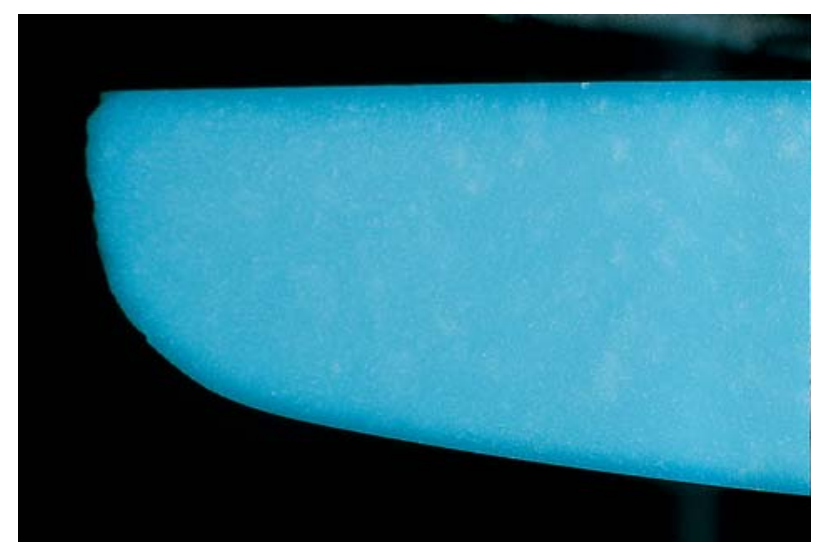

Figure 6. This cross section of a cabochon that was surface treated to improve color shows a narrow rim of more saturated color. The depth of this rim ranged from 0.2 to $0.5 \mathrm{~mm}$ in the samples we examined. Photomicrograph by Shane F. McClure; magnified 14x.

demonstrates that the crystallite size is within the same range for both products (see Fritsch and Stockton, 1987).

Energy-Dispersive X-ray Fluorescence Spectrometry. EDXRF analyses of all the untreated and treated samples demonstrated, as expected, the presence of all the major constituents of turquoise $\left[\mathrm{CuAl}_{6}\left(\mathrm{PO}_{4}\right)_{4}(\mathrm{OH})_{8} \cdot 5 \mathrm{H}_{2} \mathrm{O}\right]$ that could be detected with our instruments (figure 9): aluminum (Al), phosphorus $(\mathrm{P})$, and copper $(\mathrm{Cu})$. Iron $(\mathrm{Fe})$, a common impurity in turquoise, was also detected in all samples. The height of the Fe peak correlated to the green component of the color (in pyrite- and ironoxide-free samples); that is, the green samples showed the most intense Fe peaks. This is consistent with the report by Cervelle et al. (1985) that $\mathrm{Fe}^{3+}$ produces the yellow component of green turquoise. Sulfur (S) was occasionally detected; its signal was stronger in pieces with pyrite (FeS) inclusions. Traces of the common transition elements titanium, chromium, and vanadium were also pre-
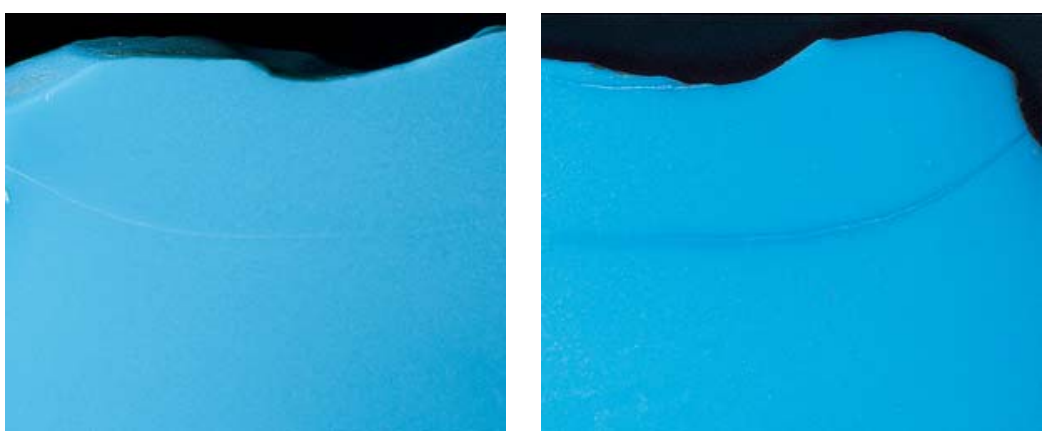

Figure 7. Blue color concentrations along fractures were seen in some of the colortreated samples. In these two slabs shown in figure 4 , the sample that was treated but not color enhanced (left) shows no change in coloration along the fracture. However, the same fracture in the adjacent slab, which was color enhanced, shows an obvious color concentration (right). Photomicrographs by Shane F. McClure; magnified 10x. 

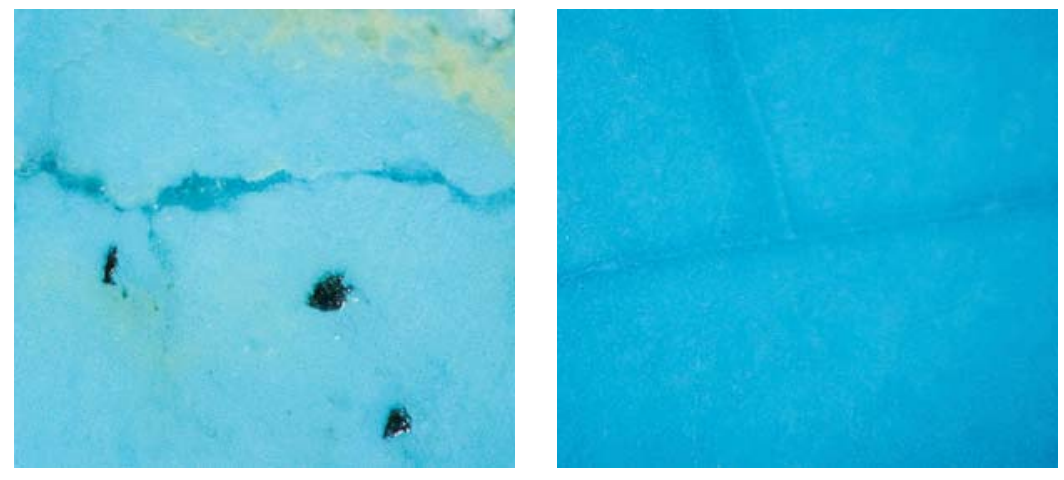

Figure 8. Color concentrations in Zachery-treated material look very different from those seen in turquoise impregnated with colored polymers. The color concentrations in the bluepolymer-filled stone (left) are restricted to the fractures. In the Zacherytreated stone (right) the color concentrations appear to diffuse into the stone adjacent to the fractures. Photomicrographs by Shane F. McClure; magnified 35x.

sent in some samples (both natural and treated). A small calcium $(\mathrm{Ca})$ signal was present in all the natural, untreated samples; this Ca peak was sometimes accompanied by a separate potassium $(\mathrm{K})$ peak, which was always smaller.

In general, the EDXRF spectra of the treated and untreated samples were similar, with one important exception: The potassium peak was much stronger in most of the treated samples than in the untreated ones, when this peak was compared to that of an element that is intrinsic to turquoise /such as phosphorus; figure 10). Although the height of the potassium peak varied from one treated piece to the next, in the vast majority of instances the amount of potassium in the treated turquoise was significantly greater than that recorded in the untreated samples.

EDXRF analyses of the four slabs cut from the same piece of Sleeping Beauty rough gave particularly interesting results in this regard. As originally recorded, the potassium contents of the untreated sample as well as the two samples that had been color treated were strong when compared to the phosphorus peak. Yet the slab that had been treated without changing its color did not show elevated potassium. Closer inspection of the untreated sample revealed a cavity in the center of the slab, which must have contained some potassium-bearing compound. When the untreated sample was analyzed in an area away from the cavity, the potassium content was much smaller. Electron microprobe analyses of these four slabs were consistent with the later EDXRF results. In addition, systematic variations in the total wt.\% oxides measured by microprobe analysis in these four slabs indicated a decrease in porosity with increasing intensity of treatment.

EDXRF analyses were also performed on the four Sleeping Beauty cabochons that were cut in half, with one half treated for a specific result and the other half left untreated. As was the case with the slabs, the two stones that were color treated showed elevated potassium, and the two cabochons that were treated without producing any effect on their color did not.

Because the three non-color-treated samples described above (the slab and the two cabochons) lacked elevated potassium contents, we decided to test some additional samples that we knew were similarly treated (i.e., for durability only, not for color) to determine if the increase in potassium occurred only in color-treated stones. Mr. Foutz loaned us 13 samples of irregular slabs from China, Mexico, and Arizona that he had treated specifically for durability/porosity but not for color. These irregular slabs ranged from green to blue to very light blue (a color the turquoise trade sometimes calls "white" turquoise) and had various amounts of matrix present. We specifically requested specimens of varying qualities and localities different from those of the three stones described earlier, which were all high-quality material from the Sleeping Beauty mine. Of these 13 treated samples, 10 showed significantly elevated potassium levels. The other three showed much smaller $\mathrm{K}$ peaks, but these peaks were still slightly stronger than those in the untreated turquoise we have tested. These results suggest that the porosity of the starting material helps determine whether or not a piece of treated turquoise will show elevated potassium with EDXRF. It was primarily the high-quality treated material that lacked elevated potassium levels, possibly because such material is less porous.

Three of the treated samples in table 1 (one high quality, and the other two medium quality) also lacked the $\mathrm{K}$ peak in their EDXRF spectra.

X-Ray Diffraction. Analyses of the one untreated and two of the treated Sleeping Beauty slabs revealed no significant differences among the three samples. This proves that no new minerals (other than, possibly, turquoise) were precipitated in the treated turquoise, and the cell dimensions remained unchanged. 


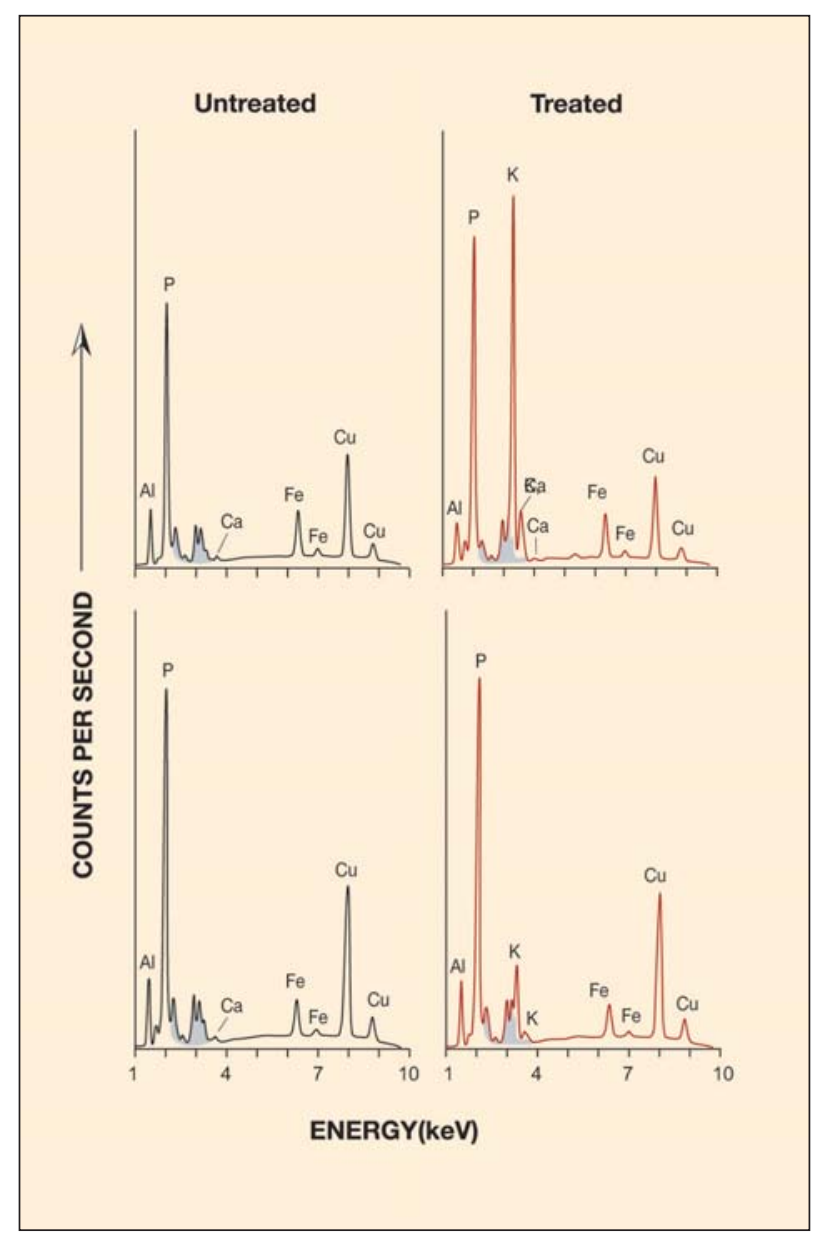

Figure 9. The EDXRF spectra for untreated turquoise from various deposits were very similar; those shown here (left) are from the Nevada Smith mine (top) and the Sleeping Beauty mine (bottom). A small potassium peak is sometimes present in the untreated material, but it is always smaller than the calcium $(\mathrm{Ca})$ peak. In contrast, the Zachery-treated turquoise (right) usually shows potassium peaks, which are much higher than in the untreated turquoise. The highest and lowest potassium peaks that we detected in the treated material are shown at the top and bottom, respectively. Note: The shaded peaks are artifacts of the instrumentation, and should be ignored.

Oxalic Acid. Mr. Foutz (pers. comm., 1998) told us about a simple - but destructive - test that may distinguish untreated from Zachery-treated turquoise. A small amount of oxalic acid solution is applied to the sample; if the material has been Zachery treated, a white skin usually will form on the surface. Mr. Foutz noted that this test works best on stones that have received color treatment and may not show on stones that have been treated for durability/porosity only.
To investigate this, we prepared a $20 \%$ solution of oxalic acid, into which we immersed one half of each of the three Sleeping Beauty cabochons treated by the different methods. We also tested an untreat-

Figure 10. These EDXRF spectra of the "Emerald Valley" samples shown in figure 3 demonstrate the potassium enrichment in the treated halves (red line) compared to their untreated counterparts (black line). To facilitate comparison, the spectra have been normalized according to the height of their phosphorus $(P)$ peaks. For the treated samples, the potassium $(K)$ peak is small in the highquality sample $(A)$, and becomes progressively larger in the medium- $(B)$ and low-quality $(C)$ samples. Note: The shaded peaks are artifacts of the instrumentation, and should be ignored.

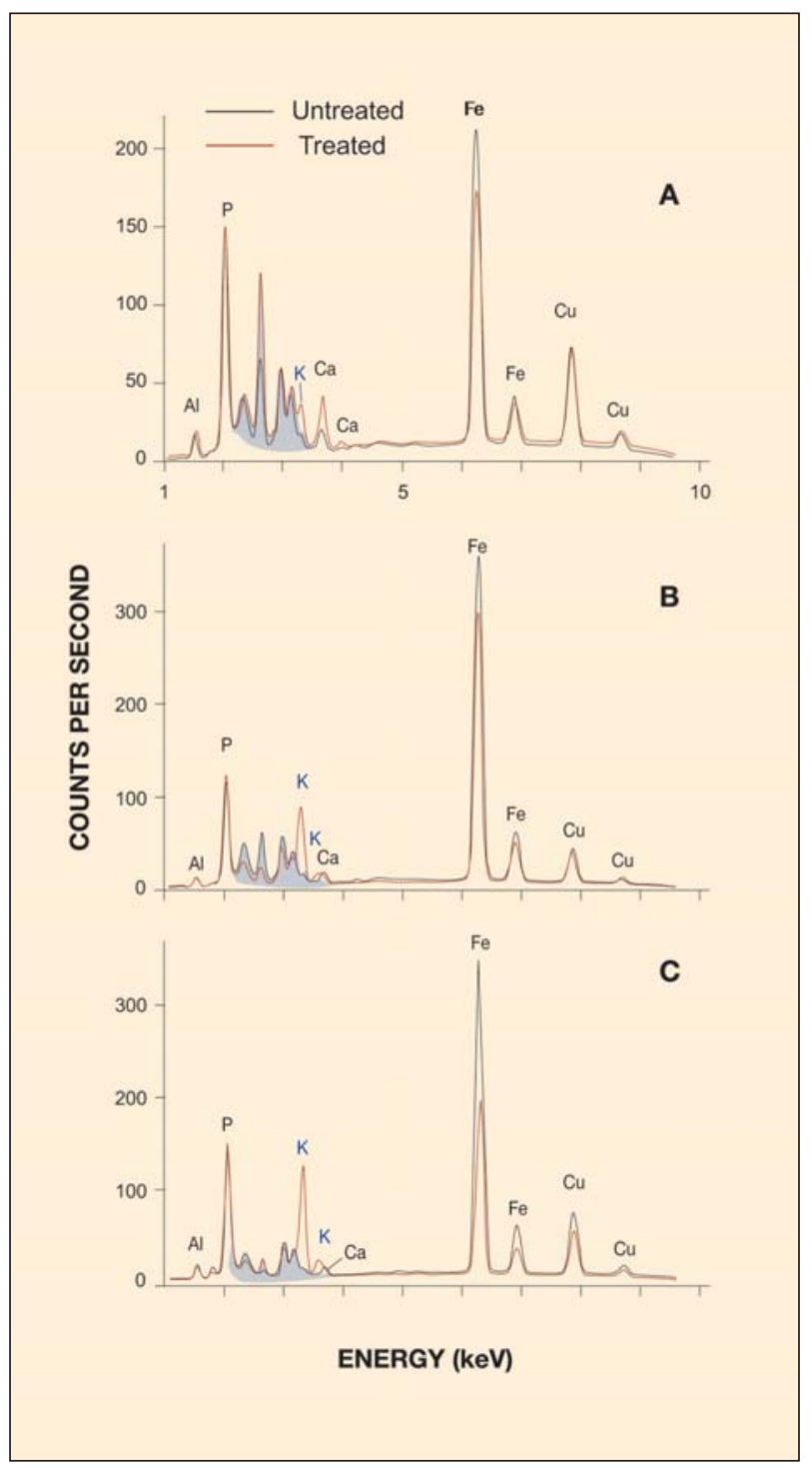


ed turquoise bead. For comparison purposes, we retained the other half of each cabochon and set aside another untreated bead of like color. After the stones had been in the solution for four hours, we rinsed them off and allowed them to dry. The untreated bead showed no apparent change, and the stone that was treated throughout but not color treated showed only a very slight whitishness. However, the stone that was treated throughout and then color treated showed a definite lightening of the blue color, and the stone that was only color treated showed a dramatic change to pale blue (figure 11). The porosity of all of the treated stones was also increased, proportional to the amount of visible reaction to the acid. This was evidenced by the fact that the stones were now sticky to the touch. These results are consistent with the information we received from Mr. Foutz. Microprobe analyses performed on one of the color-treated Sleeping Beauty cabochons revealed that the enriched potassium at the surface of the treated control half was absent from the half that was immersed in oxalic acid. They also confirmed that the immersed half showed an increase in porosity.

We performed another variation of this test by placing a small drop of solution on several polished slabs of treated turquoise. Minutes to hours were required for a reaction, and the acid left a mark that was considerably larger than the original spot of acid applied because the liquid spread on the surface of the sample. Note that it is very difficult to perform this test on curved surfaces, since the acid runs off before it has time to react with the turquoise. The white film that forms as a result of this procedure does not wipe off, and repolishing is required to return the stone to its original condition. Therefore, this test is destructive and should be used only with that limitation in mind.

\section{DISCUSSION}

Identification by Gemological Tests. Zachery-treated turquoise cannot be identified using classical gemological methods. Its gemological properties completely overlap those of natural turquoise.

The only gemological clues to the presence of this treatment are visual in nature and quite subtle. These include a slightly unnatural color (in those stones that have been color treated) and a very highquality polish. These clues are not proof of treatment, but they are indications that the average gemologist might see in the course of a visual examination. The presence of blue color concentrations along fractures and into the adjacent turquoise is another indication of Zachery treatment.

Identification by Advanced Testing. The midinfrared spectra of untreated and Zachery-treated turquoise showed no significant differences. The most effective method of identifying Zachery-treated turquoise is chemical analysis. Specifically, EDXRF revealed that the vast majority of the Zachery-treated samples in this study contained significantly more potassium than natural, untreated turquoise (again, see figure 10). These results confirm observations made by the senior author (EF) after examining the original samples in 1990. Only six of the 55 Zachery-treated stones tested by EDXRF (including the 13 samples not shown in table 1 because they were not fully characterized) did not show a higher potassium content than that seen in the untreated turquoise. We know from Mr. Foutz that three of these exceptions were treated without improving their color. We do not know the intended effect of the treatment on the other three samples. What is most important is that all the stones that revealed a high potassium content were indeed Zachery treated.

Porosity and the Treatment Process. In his 1998 letter to the authors, Mr. Zachery stated that the treated material "has not been impregnated with any wax, oil or lacquer." Our studies support this statement. However, this does not exclude the possibility that the treatment might be adding other components, which affect the porosity of the turquoise.

To understand how the filling of pores in a mineral can affect its appearance, it is necessary to understand how light reflects off materials of differing porosities. The visual appearance of porosity in materials such as turquoise is equivalent to that of a material containing small bubbles of air (of much lower R.I.) scattering light. If the voids are larger than the wavelength of visible light (i.e., a micron or more on average), then the white light that is scattered will recombine, giving a white, cloudy, or milky cast to the stone (Fritsch and Rossman, 1988). This is indeed what we observe in all natural, untreated turquoise. The same phenomenon gives rise to the white color in milky quartz (scattering by microscopic fluid inclusions). Even if the material is strongly colored, scattering will produce a lighter color. Hence, a dark brown beer has a very light-colored foam, because the myriad microscopic air bubbles scatter light efficiently, and the walls of the 
bubbles are very thin. Conversely, if the voids are filled, a significantly darker and more saturated color will be observed. A similar phenomenon is seen when a piece of colored fabric is partially immersed in water: The wet area becomes much darker and more saturated than the dry area, because the voids in the weave (its "porosity") are filled with water, thus considerably reducing the light scattering. This is what we believe we are seeing in Zachery-treated turquoise, and what is known to happen in polymer-impregnated turquoise.

One scenario that would be consistent with our observations is that turquoise is being grown in situ within the porous areas during treatment, with potassium being an aid to or by-product of the process. Alternately, the treatment may use the natural porosity of untreated turquoise to introduce a substance that helps make the material more cohesive. These scenarios would reduce the porosity of the turquoise and thus might improve the color in some specimens, much in the same way that the filling of porous chalky turquoise with polymers improves its color. These theories are best supported by the fact that the treated turquoise no longer accepts contaminants such as oils, and that the quality of the polish is improved.

The lack of potassium in some treated samples may be due to the low porosity of the starting material. If the turquoise has little or no porosity before treatment, then it will be more difficult to introduce a foreign substance. Hence, even if such a piece has undergone the full treatment process, it may not show the presence of potassium.

Another explanation is that turquoise that is nonporous or only slightly porous will not allow the potassium to penetrate until the treatment is concentrated enough to improve the stone's color. This would be consistent with the fact that three of the stones that did not show an increased potassium content were known to have been treated without improving their color. These stones were all highquality material and demonstrated the reduced porosity characteristic of this treatment.

Gemological Nomenclature. This type of treatment presents some nomenclature problems for gemologists. In the colored stone trade, treatments that affect color are often perceived more negatively than those that affect clarity or other characteristics. The problem with material treated by the Zachery process is that, while in the vast majority
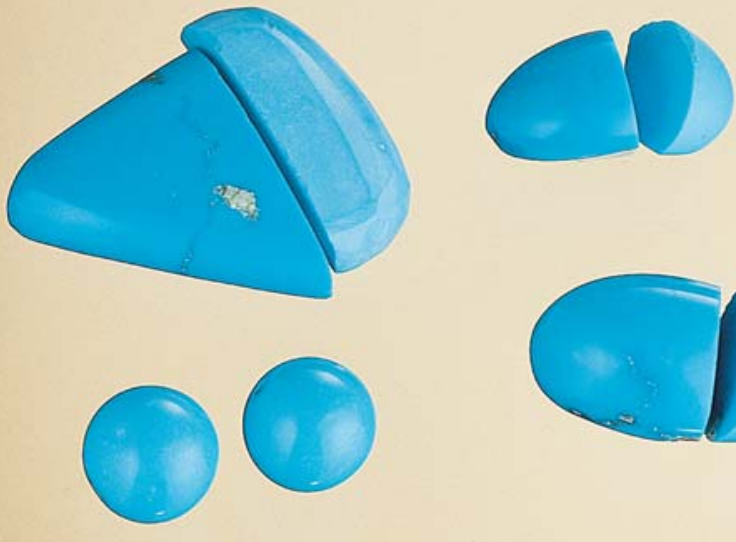

Figure 11. An oxalic acid solution can be used to detect some of the Zachery-treated turquoise. For each pair, the sample on the right was immersed in oxalic acid for four hours. Shown clockwise from the lower left, the samples are: untreated (beads); treated throughout and left natural color; treated throughout and then color treated; and color treated only. Photo by Maha DeMaggio.

of cases we can tell by chemical analysis that a stone has been treated, at this time there is no definitive way to determine whether its color has been affected. One can usually assume that stones that show blue concentrations in and near fractures have been color treated, but not all of the turquoise that has been color treated by the Zachery process shows these concentrations.

Mr. Foutz sells his material as "enhanced" turquoise, to differentiate it from treated material that is referred to as "stabilized." Unfortunately, as discussed above, we do not know exactly what is happening to the turquoise when it is treated by this process. In fact, Mr. Foutz admits that he and Mr. Zachery do not know the exact mechanism that is taking place. This creates a nomenclature problem for gemological laboratories, where concise descriptions of treatments are essential. Until more is known about the process involved, the GIA Gem Trade Laboratory will continue to call this material "Treated Natural Turquoise."

\section{CONCLUSION}

Zachery-treated turquoise cannot be detected by standard gemological techniques, although a slightly unnatural color and blue color concentrations in and around fractures are indications. Bleaching after 
exposure to oxalic acid may also indicate treatment, but this is a destructive test. On the basis of the large number of samples we tested from various localities, we have demonstrated that the vast majority of Zachery-treated turquoise can be identified by relatively high potassium levels. However, chemical analysis requires access to advanced technology such as EDXRF spectrometry or microprobe analysis; such instrumentation is available in only the most sophisticated gemological laboratories. The presence of potassium as the only detectable additive is unique among gem treatments.

Acknowledgments: The authors thank the late Pat Troutman of the Hope Franklin company, Prescott, Arizona, for first bringing this material to their attention. Special thanks go to Sterling Foutz

(sfoutz@earthlink.net) of Sterling Products, Prescott, for providing numerous samples and valuable information. We are also grateful to Phil Owens, of the GIA Gem Trade Laboratory in Carlsbad, for his assistance and information regarding the cutting and polishing of this material; and to Shane Elen, of GIA
Research, for gathering EDXRF data. Dr. Frank Hawthorne, at the University of Manitoba, kindly provided electron microprobe analyses and $X$-ray diffraction data.

This article is dedicated to the memory of the late Bob Kammerling, our friend and colleague.

\section{REFERENCES}

Bariand P., Poirot J.-P. (1985) Larousse des Pierres Précieuses. Larousse, Paris, France, pp. 242-249.

Branson O. (1975) Turquoise, the Gem of the Centuries. Treasure Chest Publications, Santa Fe, NM.

Cervelle B. (1985) Turquoises: les bonnes, les brutes et les traitées. La Recherche, No. 163, pp. 244-247.

Dontenville S., Calas G., Cervelle B. (1986) Etude spectroscopique des turquoises naturelles et traitées. Revue de Gemmologie a.f.g., No. 85, pp. 8-10; No. 86, pp. 3-4.

Fritsch E. (1990) "Zacharia" treated turquoise. Internal GIA Research memo, April 19, 1990.

Fritsch E., Stockton C.M. (1987) Infrared spectroscopy in gem identification. Gems Æ) Gemology, Vol. 23, No. 1, pp. 18-26.

Fritsch E., Rossman G.R. (1988) An update on color in gems. Part 3: Colors caused by band gaps and physical phenomena. Gems «) Gemology, Vol. 24, No. 2, pp. 81-102.

Liddicoat R.T. Jr. (1987) Handbook of Gem Identification, 12th ed. Gemological Institute of America, Santa Monica, CA.

\section{Get Your Complete Set of 1998 Issues}

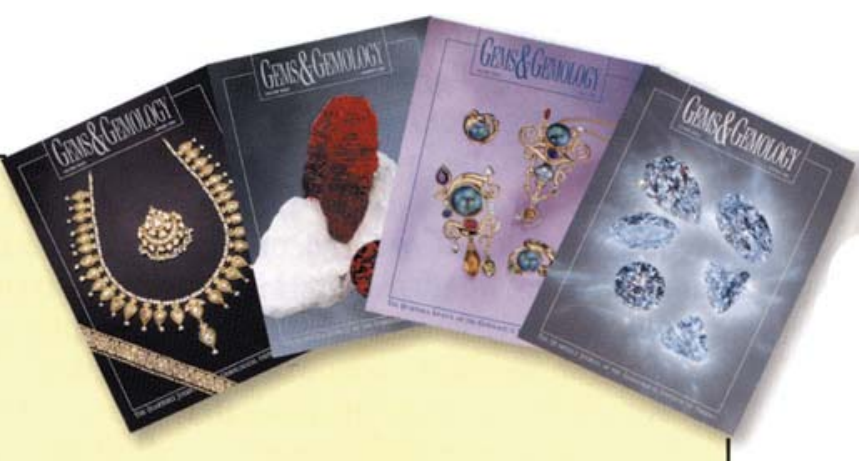

That's more than 320 pages of cutting-edge trade news and scientific research from some of the world's keenest gemological minds!

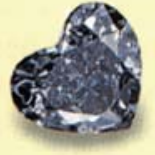

SAVE $20 \%$

Off the Single-Issue Price

\section{ONLY $\$ 40^{*}$}

For all Four Issues

* $\$ 48$ in Canada, $\$ 60$ elsewhere

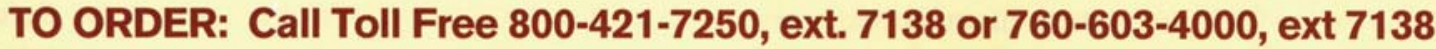

